\title{
Consideration and Exploration on Improving the Quality of Graduation Design Under the Background of Engineering Certification
}

\author{
Guoyan Liu ${ }^{1}$, Jincai Zhao ${ }^{1, *}$, Yanan Zeng ${ }^{1}$, Yong $\mathrm{Wei}^{1}$ and Haiyun $\mathrm{Wu}^{1}$ \\ ${ }^{1}$ College of Technology, Tianjin Agricultural University, Tianjin 300384, China \\ *Corresponding author.Email: jincai.zhao@qq.com
}

\begin{abstract}
In order to improve the quality of the graduation design of Tianjin Agricultural College and better meet the quality certification standards of engineering education, this thesis considers and explores the following aspects, such as the topic selection of the graduation design, the standardization of the thesis, and the cultivation of the ability to solve engineering problems and so on. Based on the existing problems and combined with engineering education quality certification standards, reform measures have been proposed to improve the quality of graduation design, so as to ensure that graduates meet the established quality standards recognized by the industry and optimize and perfect the professional talent training system.

Keywords: Engineering certification; Graduation Design; reform; standardization
\end{abstract}

\section{INTRODUCTION}

Engineering education professional certification is an internationally accepted engineering education quality assurance system. It is an important foundation for the realization of international mutual recognition of engineer qualifications and professional education. It is the standardization and qualification evaluation of professional education received by those who are about to enter the industry. The core is to ensure that graduates meet the established quality standards recognized by the industry, and then achieve the substantial equivalence of the quality of talent training. As a graduation design in the engineering education quality certification standard, it is the key to cultivating students' ability to solve complex engineering problems and an important part of engineering professional education. It plays an important role in cultivating students' professional qualities and the ability to solve complex engineering problems. It is also a test of the comprehensive practical application and training quality of the professional knowledge learned by students at the undergraduate level.

As the last practice link of undergraduate talent training, graduation design also combines engineering education certification standards and supplementary standards for measurement and control. This article focuses on the four aspects of topic selection, thesis writing, the ability to solve engineering problems, and the integrity of the thesis. Combining the main problems and analysis of the graduation design of our school's measurement and control technology and instrument majors, a series of effective reform measures are proposed.

\section{ANALYSIS OF THE MAIN FACTORS AFFECTING THE QUALITY OF GRADUATION DESIGN}

The main factors that affect the graduation design are: topic selection, thesis writing, problem-solving ability training, and the integrity of the thesis. The following four aspects will be analyzed in detail.

\subsection{Topic selection}

The thesis should be selected in four aspects: training objectives, discipline frontier, difficulty and workload. The selected topic must ensure that the research objectives match the training objectives of the major, the practice ability of the project can promote the achievement of graduation requirements and the design direction is consistent with the professional direction. Besides, the topic selection is oriented to the front of the subject, the research content is moderate and the workload meets the requirements of undergraduate graduation design.

(1) The training goal is to combine the needs of social economy and regional development and the specialty orientation with the characteristics of the Department. Through undergraduate training, students can achieve the expected state or achievement of the training goal in their career development five years after graduation while meeting the graduation requirements[2]. Therefore, in addition to meeting the graduation requirements, the topic selection should also be able to exercise students engineering consciousness, and make them understand the problems which they need to face and solve in their work 
after graduation, as well as the social responsibilities they need to bear.

(2) The frontier of the discipline represents the development trend of the discipline and the key scientific problems in the current development. The research height of the topic selection of undergraduate graduation design should not be too high, but it should be combined with the professional development and the frontier of the discipline, and keep pace with the development of the times, so as to help students meet the market demand when they go out of the campus. At the same time, it can promote students to master and use modern technology and tools, and cultivate and improve students' application and engineering practice ability of modern technology and tools.

(3) The difficulty of topic selection is not only related to whether the graduates can successfully complete the graduation project, but also has a great impact on whether they can achieve the expected practical training effect. If the topic is too easy, it cannot effectively test the ability of students to use knowledge and solve practical engineering problems, while if it is too difficult, it will affect the process of graduation design, and even beat the enthusiasm and confidence of students.

(4) The workload of topic selection should be moderate. The graduation project is not only a comprehensive and systematic application of the knowledge learned in the past four years, but also an engineering training to extend and expand the learned knowledge and solve practical problems. If the workload is too small, the coverage is limited. If the workload is too large, it will be too difficult to study intensively and achieve the expected training effect in a limited time.

The topic selection should be closely combined with the professional training objectives, focus on the professional development and the frontier of the discipline, and keep pace with the needs of scientific and Technological Development and social development. The workload and difficulty of topic selection are the embodiment of the breadth and depth of topic selection. The topic selection of graduation design should have a certain breadth, but also appropriate difficulty and height. Graduation design is not only a process of comprehensive exercise, but also a process of testing professional training results.

\subsection{Graduation design writing}

The writing of graduation design is not only the carding and summary of the design or research content, but also the process of using, consolidating and improving the professional knowledge. It can exercise and improve students' writing and expression ability and cultivate students' ability to raise, analyze, solve and summarize problems in solving engineering problems.

For undergraduate thesis writing, one of the most important things is the normative training of thesis. Although students have a lot of reading and writing experience, thesis writing is very different. It not only requires students to present the content of the design or research in a clear and comprehensive way, but also to express it in standard format, terms, charts, formulas, etc. from a professional perspective. The standardization of graduation thesis involves many factors, such as whether the abstract includes the research purpose, method, result or conclusion of the design content, and whether it reflects the innovation, theory or application value of the design or research [3]. Standardization is the premise to ensure the writing quality of graduation design, which must be written in accordance with the national standards and the corresponding standards of colleges and departments. High quality graduation design should be the unity of form and content, not only follow the standardization of format and the standardization of detail expression, including formula, chart, literature citation and other aspects. We should also show the research results accurately, scientifically and normatively. It is necessary for the engineering quality training of students to grasp the standardization of graduation design.

Graduation design, as an important practice link of undergraduate talent training, is not only to use the professional knowledge to analyze and solve practical problems according to the actual needs, but also to cultivate and train students' academic and engineering literacy, and learn to use various modern technologies and tools to solve complex engineering problems. It involves literature review, problem posing, solution design and demonstration, scheme implementation and verification, etc.

Literature retrieval and reading is the primary content of graduation design, which plays a key role in the completion quality of graduation design. Whether in the process of topic selection, design or research, or in the process of thesis writing, literature retrieval and reading often directly affect the value or significance of design or research. Reading and refining the contents of the literature effectively can provide scientific and authoritative reference and help students master the writing methods and norms, stimulate the students' innovative thinking and improve the quality of graduation design.

\subsection{Problem-solving ability development}

The proposal of the problem is to combine the design or research direction given by the instructor, on the basis of referring to the relevant literature in recent years, make clear the main problems to be solved in the design topic. It can train students' ability to analyze problems. Because it can further targeted reference and in-depth mining of relevant technical data, combined with the existing research basis at home and abroad to put forward their own ideas or solutions. The development of this work is very beneficial to the training of students' problem analysis ability.

The design and demonstration of the solution is one of the main ways to train students' ability to solve complex engineering problems. Engineering education professional certification focuses on the basic ability of students to analyze and solve complex engineering problems by using their professional scientific theory and technical methods. 
To solve complex engineering problems, it is necessary to carry out in-depth principle analysis and comprehensively apply professional knowledge and skills[4]. The paper proposes the solution based on the relevant literature, and demonstrates the solution by investigation, discussion or simulation of key links. This link can promote the development of graduation design and improve the students' ability to solve complex engineering problems.

\subsection{The integrity of graduation design}

The integrity of graduation design is particularly important for engineering majors, such as measurement and control technology and instrument. In addition to obtaining effective conclusions through software and hardware design, experiments, and the analysis process of judgment, reasoning, and induction of experimental data or results, it has clear organization Reflecting the value or significance of graduation project objectively and normatively is also the general argument of graduation project. At the same time, the complete presentation of the design or research content often needs the system hardware structure diagram, circuit schematic diagram, program flow chart, program source code and other appendix content as support. These materials not only play a good role in supporting the thesis, but also can train students' necessary technical literacy to solve complex engineering problems. The integrity of graduation design is conducive to further training and strengthening the ability of graduates to engage in scientific research and engineering work.

\section{THE MAIN PROBLEMS AND ANALYSIS OF THE GRADUATION DESIGN OF MEASUREMENT AND CONTROL TECHNOLOGY AND INSTRUMENT MAJOR IN OUR UNIVERSITY}

Analysis of 210 graduation designs of our major from 2018 to 2021 , it is found that the overall quality of graduation designs is acceptable, but there is still a large room for improvement compared with the requirements of engineering certification. In addition to a few topics that focus on theoretical research and deviate from the training objectives of applied talents, other topics can better meet the professional training objectives with moderate workload and difficulty. Most of the problems focus on the writing standard, integrity of the paper and the lack of ability to solve engineering problems

\subsection{The standardization of thesis writing needs to be further improved}

Standardization is the premise to ensure the quality of graduation design writing, and also plays an important role in the cultivation of comprehensive ability of undergraduate application-oriented talents. From the inspection results, most graduation designs have more or less some non-standard details, the most significant is that the processing of drawings and tables is not appropriate and standard, it shows that the quality of students in engineering specifications needs to be further strengthened. The reasons are as follows: (1) in his life, he was used to the pictures and tables in the book, paid more attention to the content, and often ignored the format specification; (2) In the early stage of curriculum design, charts are also used, but they are less involved, and some format requirements are not completely unified with the graduation design, which does not play a pre training effect.

In addition, through the analysis of the abstracts of graduation design, it is found that about $40 \%$ of the abstracts are not standardized in writing, not comprehensive in content or not rigorous in expression, such as too many heads and few tails, too detailed or not comprehensive in research methods, and not accurate in expression of results or conclusions. For example, there is a description in the abstract of a graduation project: "this design proposes a set of autonomous navigation horticultural robot system, which obtains the attitude information of the car through BDS / GPS module, and uses ultrasonic and infrared sensors to judge obstacles; Through the design of autonomous navigation control and obstacle avoidance algorithm based on multi-source information fusion, the control of gardening robot platform is realized The former is the autonomous navigation horticultural robot system, but the latter is based on the control of the horticultural robot platform, and the control content is not clear enough, and the expression is not rigorous enough.

The main reasons for the problems are as follows: (1) the students lack the experience in thesis writing. Although they have finished the report writing four times, they have not been involved in the training of abstract writing; (2) At present, a tutor often guides more than one graduation design student, and the focus of his work is more on the guidance and control of the content of the design, and the review time of the thesis is relatively concentrated, so it is difficult to keep improving. In addition, the students' implementation of the guidance and modification opinions is sometimes not thorough, which also causes the above phenomenon.

\subsection{The integrity of the thesis is deficient}

It is found that most of the graduation projects cover the design of software and hardware, experiments, judgment, reasoning and induction of experimental data or results, and effective conclusions are drawn. However, the hardware structure diagram, circuit schematic diagram, program flow chart and program source code of the system involved in the design are often not complete, and some of them appear in the text. It shows that there are still some deficiencies in training students to solve engineering 
problems. The reasons are as follows: (1) there are some deficiencies in the teaching design of graduation project, but no unified standard; (2) students are not aware of the integrity of graduation design, and their engineering literacy is poor.

\subsection{Insufficient training of students' ability to solve engineering problems}

Engineering education professional certification requires graduates to apply the basic principles of mathematics, natural science and engineering science to identify, express and analyze complex engineering problems through literature research in order to obtain effective conclusions. However, from the recent four years of graduation design (Thesis), there is a widespread lack of students' ability to solve problems. For the design of measurement and control system, most of the problems are lack of feasibility analysis, the verification of the design scheme is not enough, the integrity of the problem is not enough, the practicality is not strong, and it cannot meet the requirements of engineering certification for the ability to solve complex engineering problems. For theoretical research topics, limited to the limitations of undergraduate professional knowledge and research ability, the paper cannot well reflect the ability to use basic knowledge and professional knowledge to solve engineering problems, However, due to the limited knowledge and ability of undergraduate students and the lack of practical experience, some graduation thesis are not suitable for practical application, which often stay at the level of theoretical research and cannot reflect the ability to expand, extend and solve engineering problems by using the knowledge learned.

\section{THOUGHTS AND REFORM MEASURES ON IMPROVING THE QUALITY OF GRADUATION DESIGN}

\subsection{Introduce scientific and technological paper writing into the curriculum system}

In Article 10 of the engineering education certification standard, it is required to be able to effectively communicate with peers in the industry and the public on complex engineering problems, including writing reports and design manuscripts, making statements, clearly expressing or responding to instructions. It can be seen that the training of writing and writing ability is an essential part of undergraduate talent training, and it is also an important measure to improve the quality of graduation design. Therefore, in the design of the new training plan, literature review and scientific and technological paper writing are introduced, and the training of literature review, scientific and technological paper writing and standardization are carried out in the form of special lectures.

\subsection{Further strengthen the cultivation of engineering problems and engineering consciousness}

In the past three years, students have participated in more than 60 electronic design competitions at all levels, including more than 50 provincial and ministerial level and above. Meanwhile, they have actively encouraged and guided students to carry out application and research of College Students' innovation and entrepreneurship training projects. In the past three years, they have been approved more than 30 national, municipal and university level projects. In the professional practice teaching, the practice teaching reform is carried out continuously, and the practice contents of basic professional skills training, production practice and two professional comprehensive courses are adjusted in series, that is, in addition to the learning and use of common instruments and meters in the professional basic skills training, On the basis of welding skill training, the module circuit used in the welding production practice is introduced; The function modules of production and debugging in production practice are used in the design of comprehensive courses for the following two majors. It can not only effectively save the consumption of consumables, but also enable students to have a complete understanding of the whole production process, and enhance students' understanding of engineering problems and the cultivation of engineering consciousness. At the same time, in the course design report link, the integrity of the design report and the unification of the report specification and the graduation design are further increased. Through four times of course design report training, the foundation is laid for the improvement of the quality of the graduation design thesis.

\subsection{Strengthen the cultivation of students' ability to solve engineering problems}

Eight of the 12 standards for engineering education professional certification are related to complex engineering problems. Cultivating students' ability to solve complex engineering problems is not only an important standard for engineering education certification, but also an important guarantee for cultivating high-level engineers [56]. Graduation design is an important way to cultivate students' ability to solve complex engineering problems. Therefore, in the graduation design link, it is necessary to strengthen the cultivation of students' ability to put forward problems, analyze and solve problems, especially complex engineering problems, by using the knowledge and skills they have learned. This is not only in line with the certification standards, but also conducive to the achievement of training objectives, It will lay a solid foundation for improving students' practical work ability 
after graduation. Therefore, it is necessary to strengthen the guidance teachers' accurate interpretation of the meaning of "complex engineering problems" in the engineering education certification label, and reasonably use the perspective of engineering problems in the graduation design, such as: the topic selection should have the exploratory and research characteristics of complex engineering problems; Pay attention to the use of relevant engineering principles and modern technology or professional tools in the design scheme; The solution should consider technology, engineering and other social, cultural and environmental factors. In addition, adjusting and improving the graduation design outline and integrating complex engineering problems into the content requirements and implementation process of graduation design are conducive to improving students' engineering practice ability of analyzing and solving problems [7]

\section{CONCLUSION}

It is not only the need of engineering education professional certification, but also an important part of professional construction and reform to find the deficiencies of graduation design and improve its quality. The analysis of graduation project can not only reflect the training quality of applied technical talents, but also point out the direction for the continuous optimization and improvement of professional talent training system. In this comprehensive practice teaching link, which integrates exploration, learning and innovation, students' engineering practice ability and good engineering literacy can be further cultivated, which lays a foundation for students to enter the society, be competent for the role of the industry and have a better development space. In the future, the major will continue to strengthen quality control, explore more effective graduation design management and evaluation system, and ensure that the quality of graduation design meets the requirements of engineering education professional certification.

\section{ACKNOWLEDGMENT}

This work was supported by Research and reform project of undergraduate education and teaching in Tianjin Agricultural University (2018-A-07).

\section{REFERENCES}

[1] Hua Ertian, Ji Weirong, Wu Xiangming. The exploration and practice of engineering innovative talents training under the background of China's accession to the "Washington Agreement"[J]. Chinese Higher Education Research, 2017, (1):82-85.

[2] China Engineering Education Professional Certification Association. Engineering Education Certification Standard (2017 Edition) [S]. 2017.

[3] Wu Jun, Qin Fuli. Exploration on the improvement of graduation design based on the certification of engineering education[J]. Textile and Apparel Education, 2020, (12):539-543.

[4] Jiang Xiankai. Exploration of the improvement of graduation design based on the certification of engineering education[J], 2019(39): 126-127.

[5] Liu Xuming. Practice teaching reform and practice of electrical engineering specialty for local application oriented Undergraduate Based on "Four Integration" [J]. University education, 2021(06):71-73

[6] Li Rui, Cao Rongmin, Yu Di. Practical Teaching Research of New Engineering Courses to Cultivate the Ability to Solve Complex Engineering Problems[J]. Education Teaching Forum, 2020(13):84-85.

[7] Wu Jun, Qing Fuli. The exploration of improving the quality of graduation design (thesis) under the background of engineering education professional certification[J]. Textile and Apparel Education, 2020(12):539-543. 